\title{
An Analysis on the Relationship between Parenting Styles and Self Esteem of Students of a University in Malaysia: A Case Study
}

Ooi Shok Hong

Choi Sang Long

\author{
Rabeatul Husna Abdull Rahman \\ Faculty of Management, Universiti Teknologi Malaysia \\ Email:s.hong_89@hotmail.com, slchoi@utm.my, husna@management.utm.my
}

Doi:10.5901/mjss.2015.v6n4s3p300

\begin{abstract}
This research examines about the relationship between parenting style and self-esteem among students in a faculty at a Public University in Malaysia. The study involved 120 students and was analysed by using the descriptive and inferential statistics. Parenting styles was measured by "Parental Authority Questionnaire" (PAQ) instrument while the self-esteem was measured by "Rosenberg Self-Esteem Inventory" (RSES). The data were analyzed by using the "Statistical Package for Social Science" version 18.0. All of the data were analyzed using Pearson correlation and descriptive statistics. As a conclusion, the results show that permissive parenting style is the dominant parenting style used by the parents of university students. In addition, most of the university students have high level of self-esteem. Besides this, it is also found that there is a significant relationship between parenting style and self-esteem among university students. The study is also found that there is a positive relationship between authoritative and permissive parenting style with self-esteem. Meanwhile, the study found that the authoritarian parenting style has a negative relationship with students' self-esteem
\end{abstract}

Keywords: Parenting style; self-esteem; authoritarian; authoritative; permissive.

\section{Introduction}

Adolescents is the generation that will lead our country in the future. Various expectations have been placed in them in order to motivate them to become useful individuals that can contribute to the welfare of nation (Nuraini Nawwar, 2009). However, recently there are many of poor academic achievement students and hence the elderly begin to concern about this issue. Elderly has found out that most of the poor achievement students are come from problematic family and thus reducing their knowledge (Elham, Siti Nor, Rumaya \& Mansor, 2012).

Adolescents who have low academic achievement is due to problematic family and low self-esteem (Kamilah Noordin, 2005). They are always looked down by friends and lack of affection from the nearest person. Therefore, they are always inferior, irritability, not interested in learning and involved in anti-social (Wei, 2008).

This incident gives a great challenge to the parents. Parents are the role model and the major person for adolescents to build their character, personality, morals and faith of the children (Salasiah Khairollah, 2011). Besides this, parents are the source of inspiration for the children along their development process (Salasiah Khairollah, 2011). Despite the parents like it or not, they cannot escape from being involved in the children development process. In other words, parents should be involved in the world of children's lives. Children need role models so that the goodness of related examples can be followed and practice in their lives. Family life is the beginning of school for children to establish themselves.

Parents are the most important examples and reference materials for children (Kamilah Noordin, 2005). By interacting with parents, children begin to know themselves and gain experience as a preparation for the challenges in future life. The experience of interacting with parents and family also determins the attitudes and behavior of children towards others and society (Smith, 2007). The role of parents to enhance children's potential can be realized through the concept of effective parenting styles (Azizi \& Jaafar, 2006). The aim of parenting styles is to shape the character of the children so that the behavior shown is appropriate to the needs of parents, families and communities.

Parents play an important role in shaping adolescents personality, this is because the inappropriate interaction will affect the adolescents in developing a good personality (Wei, 2008). The role of parents is considered important because 
the personality formed in childhood will affect the personality formation in adolescents (Caporella, 2007). In addition, parents who can interact with adolescents in friendly way and use appropriate discipline will help the adolescents to develop a good personality.

Undeniably parents and family play a very important role in the development of adolescents thought, feeling and behavior. Parenting styles practice by parents decide the successful or failure of adolescent. Although adolescents are able to think about the pros and cons of a situation, but the affect of early interaction can help effectively. This is meant that the parenting style is important to adolescents' mental development. Therefore, this study is undertaken to identify the parenting style and students' self-esteem among university students.

\subsection{Parenting Style}

Baumrind (1991) states that there are two important dimensions in parenting styles: demandingness and responsiveness. Expansion mechanisms that influence children's development is represented by the intersection between the two dimensions. Demandingness can be defined as the amount or degree of strictness and control exerted by parents against children, while dimension of responsiveness can be defined as the frequency of interaction and intimacy with children either positively or negatively.

Dimension of demandingness refers to a style of parenting that is associated with high level of rigor and parental controls. According to Baumrind (1996) demandingness refer to the requirement of the parents to the children so that they become more integrated in their families and communities through maturity, supervision and discipline. Parents are often decisive for all activities undertaken by students and will scold them if they do not reached parent expectation. An authoritarian parenting style is under the dimensions of demandingness which it involve obedience, conformity, parental controls and the need to respect parental authority (Huver, Otten, Vries \& Engels, 2010).

Dimension of responsiveness is related to the level of support, warmth and parental involvement. According to Baumrind (1996), responsiveness is the extent to which parents foster personality and self-affirmation in children with support or fulfil needs of adolescents. Often parents in this dimension engage and provide support to the activities carried out by their children. This types of parents can actively listen, respond, warmth and focus on adolescents.

According to Baumrind (1996) the three types of parenting styles and their characteristics are as below:

(1) Authoritative parenting styles: the characteristics of this style practice responsiveness and high demands. This parenting style leads children with rational, issue-oriented, disciplined and explain the reasons behind the rules. As stated by Maccoby and Martin (1983), the features of an authoritative parenting style is parents who know and understand self-reliance in children, encourage oral communication, involving children in making decisions and want their children to carry out responsibilities based on the needs and abilities of their family members.

(2) Authoritarian parenting style: this style displays characteristics of parents that are very strict and demanding. This style have high control and constantly demand maturity toward children, but low in nurturing and two ways communication between parents and children. Authoritarian parents limit their children's privacy and want their children to follow the rules set without any reason given. Besides this, they also impose severe punishments on children if their children break the rules or orders that have been set. As stated by Baumrind (1996), children who are treated with authoritarian parenting styles tend to be more anxious, less socializing, and less satisfied.

(3) Permissive parenting style: this style is characterized as low demanding and high levels of responsiveness. Characteristics of this style are high in fulfilment but low in maturity, control and two-way communication between parents and children. According to Baumrind (1996), permissive style is a loose style in which parents make less demand on their children, do not encourage their children to express their feelings, and do not force to control the adolescents' behavior. In fact, they do not require their children to be mature in behavior and encourage independent behavior in their children.

According to Nancy (2011), parent of permissive parenting style do not respond and control toward their children. These parents are preoccupied with their own problems without discharging the responsibilities as parents. Children who are raised by permissive parenting style are not able to control themselves, impulsive and less self-reliant. However, they are happier and speedy recovery from a stress or crisis situation as compared with children who grew up with authoritarian. 


\subsection{Self-Esteem}

Academic achievement is associated with students' self-esteem (Kamilah Noordin, 2005). Lack of confidence in achieving success in a field is closely related to someone's self-esteem (Smith, 2007). The development of a healthy self-esteem has been seen as an important indicator in psychological adjustment such as emotional, cognitive and behavioral variables (Leary \& MacDonald, 2003). Therefore, if a person has low self-esteem he will face problem in achieving success, indirectly increasing a person's problem.

According to Coopersmith (1967) self-esteem can be defined as the overall self-assessment made toward oneself. Individuals with high level of self-esteem is considered as someone who has high confidence, satisfied with himself, resilient and able to solve problems (Ross \& Zeller, 2006). Conversely, individuals with low level of self-esteem are generally more vulnerable, anxious, lonely and depressed when face problems (Ross \& Zeller, 2006).

\section{Relationship between Parenting Style and Self Esteem}

According to a study conducted by Gota (2012) students' level of self-esteem is related to parenting styles. This is because the relationship between the parents and adolescents that were built in the early stages of life can contribute to the level of self-esteem (Brown \& Dutton, 1995). In addition, Cohen \& Rice (1997) stated that the results of the study found that mothers who consistently respond to their adolescents during infancy and early adolescence can build high level of self-esteem in adolescents.

Studies show that the parenting styles are associated with the development of students' self-esteem. For example, Lee (2001) showed that different parenting styles are associated with self-esteem in adolescence. The findings of Parker and Benson (2004) showed that authoritative parenting style is associated with high level of self-esteem in adolescence. In addition, Gota (2012) also stated that parenting style used by parents influence students' self-esteem development. Therefore, parents play an important role in influencing students' self-esteem.

Chao (1994) stated that the culture determines the effect of parenting style on students' self-esteem. This is because research has shown that in western culture, authoritative parenting style brings more benefits to the adolescents' self-esteem when compared with other parenting styles (New \& Cochran, 2007). According to Mruk (2006), authoritative parenting style is more conducive and tend to develop high level of self-esteem in adolescents. However, findings of Chao (1994) shows that authoritarian parenting style are more likely to increase students' self-esteem in China. This difference is due to vary cultural practices among countries.

Most of the studies are carried out abroad and little research is done in Asians (Hsieh, 1998; Garcia \& Gracia, 2009; Cheung \& McBride-Chang, 2008). This situation causes the Asians have little understanding on the relationship between parenting style and students' self-esteem. In addition, just a few research conducted on parenting style and selfesteem on university students (Kwan, 2004). Therefore, this research aims to investigate the relationship between parenting styles and students' self-esteem among students in a faculty at $A B C$. This study is important for students to improve their academic success at university. If the research is successful, it could bring many advantages for youth, family and country.

In addition, Robiatun (2002) conducted a study to determine the pattern of parenting styles and relationship with the self-esteem of delinquents' deviant behavior. Subjects were students in Tunas Bakti, Taiping. The results showed that there is no significant relationship between self-esteem and parents' parenting styles.

Moreover, a study conducted by Kwan (2004) to 100 students at Universiti Kebangsaan Malaysia found that most of the parents practice authoritative parenting style. The findings shown that there was a strong significant relationship between authoritative parenting styles with students' self-esteem. However, authoritarian parenting style was negatively correlated to self-esteem. This shows that the higher the degree of authoritarian used, the lower the level of self-esteem. For permissive parenting style, there is a positive relationship with self-esteem. In addition, this study showed that selfesteem of male students is lower than female students.

A study was conducted by Rosmaliza (2005) regarding types of parenting styles used by mother and the relationship with children' self-esteem. The results showed no significant difference in maternal parenting styles and selfesteem among children with the mothers who are working and mothers who are not working. Results of this study show that mother's love is an essential element for the formation of children self-esteem.

A study was conducted by Wan Mohd Agil (2009) to study about the relationship between parenting style and selfesteem among students in "Sekolah Menengah Kebangsaan Agama" (SMKA). The subjects of this study consisted of 100 people of Form Four students. Coopersmith Self-Esteem Inventory (CSEI) instrument was used to measure the level of students' self-esteem while Parental Authority Questionnaire (PAQ) instrument was used to measure parenting style. 
The findings showed that parenting style has a relationship with students' self-esteem. The study found an authoritative and permissive parenting styles have a positive relationship with students' self-esteem, while authoritarian parenting style has a negative relationship with students' self-esteem. In addition, the study also showed no significant difference in selfesteem by gender.

A study conducted by Norhusna (2009) aims to investigate the relationship between parenting styles with levels of depression among the high-risk students. Quantitative data in this study were collected using two questionnaires, namely Parental Authority Questionnaire (PAQ) and Childen Depression Inventory. The results showed there was no significant relationship between parenting style and depression levels. This study also showed no significant difference by gender in level of depression among students at risk. In addition, the results showed that most dominant perceived parenting style by students at risk is permissive parenting style followed by authoritative parenting styles.

A study was conducted by Norhayati (2009) from Universiti Pendidikan Sultan Idris about the relationship between parents' parenting style with adolescent self-concept. This study aimed to examine the relationship between parenting styles and self-concept of students who live in Pahang FELDA areas. Quantitative data were collected using a Parental Authority Questionnaire (PAQ) and Culture Free Self-Concept Inventory (CFSEI). The results showed that no significant association for parenting styles with adolescent self-concept. Moreover, the results showed that most parenting style used by parents was authoritative parenting style and students' self-concept were at moderate levels.

A study was conducted by Salasiah (2011) to determine the influence of parenting styles to Islamic personality among students of Form 1 to Form 6 in a secondary school in Batu Pahat, Johor. Participants were chosen by stratified random sample and a total of 302 students were selected as respondents. The findings of the descriptive analysis showed that most of the parent were practicing authoritarian parenting style, followed by authoritative style and permissive parenting style. Inference findings showed that there is a significant relationship between parenting styles (authoritarian, authoritative and permissive) and Islamic personality.

A study was conducted by Avidan, Sarah \& Danielle (2007) to examine the relationship between parenting styles and self-esteem, depression and life satisfaction. Subjects were 272 students where 145 were male students and 127 were female students. The subjects of this study consisted of students from grade 9 to grade 11 in high school of America. The results showed that authoritative parenting style practiced by parents have significant relationship with high self-esteem and life satisfaction but low level in anxiety.

Steinberg, Blatt-Eisengant \& Cauffman (2006) conducted a study to examine the relationship of competence and adjustment among adolescents who were treated in authoritarian, authoritative and permissive parenting styles in home. A total of 1,335 subjects in this study were involved in the juvenile offense. Most of the subjects stated that parenting style practice by their parents are authoritarian and permissive parenting styles. The results of the study indicated that authoritarian and permissive parenting styles both show high scores in juvenile error.

Smith (2007) conducted a study on parenting styles and its impact on self-esteem and self-efficiency in late adolescence college adjustment. A total of 203 subjects participated in this study where 62 people were male and 141 people were female. The questionnaires used in this study were self-efficiency (GSEs), self-esteem (RSES), adjustment to college life (TRAC) and parenting style (PAQ). Results showed that children who received an authoritarian parenting style has low level of self-esteem and self-efficiency. However, children treated by authoritative parenting style have high level of self-esteem and self-efficiency. Besides this, subjects who have high level of self-esteem and self-efficiency suffer less "homesick" and show more emotions and behaviors at the college adjustment life.

Martinez \& Gracia (2007) conducted a research on 1,198 subjects in relation to the self-esteem of adolescents in Brazil that are treated by authoritarian, authoritative, permissive and neglectful parenting styles. The study found that adolescents who are treated by authoritative and permissive parenting styles associated with adolescents' selftranscendent. However, authoritarian parenting style patterns has associated with low self-esteem. Adolescents' who treated in permissive and authoritative parenting styles have high level of self-esteem if compared with authoritarian and neglectful parenting styles.

Gracia \& Gracia (2009) conducted a study to identify whether authoritative parenting style is the best parenting style for children development. Data was collected from 1,416 Spanish adolescents aged 12 to 17 years old. In this study, adolescents were classified into four parenting styles (authoritarian, authoritative, permissive and neglectful). Adolescents compared in four different criteria such as self-esteem, psychosocial, self-competence and problematic behavior. Results of the research showed that parents who adopt an authoritative and permissive parenting styles have a good relationship in self-esteem, psychosocial and self-competence. Overall, the results of this research showed that most Spain parents have adopted permissive parenting style and adolescents scored high in all of the outcomes (self-esteem, psychosocial, self-competence and problematic behavior).

Li, Costanzo \& Putallaz (2010) showed that most of the Chinese respondents received authoritarian parenting style 
comparing to the respondents from United Europe. Although majority of Chinese are treated by authoritarian parenting style, but these findings indicates that the Chinese respondents prefer authoritative parenting style which is associated with a stronger self-esteem in two cultural groups. These findings are similar to Supple and his friends study as they identify the perception of China adolescents on authoritative parenting is positively associated with self-esteem while obedience of the children (authoritarian) has a weak association with adolescents' self-esteem.

\section{Methodology}

\subsection{Respondents}

The chosen Institution of Higher Learning requested not to disclose the name of their University. Therefore, the University will be named as ABC University. Respondents in this study were students who study in the course of Industrial and Organizational Psychology. Permission to distribute the questionnaire was approved by the office of Faculty of Management of $A B C$. A total of 180 questionnaires were distributed to 172 year one to year four students and 140 sets of questionnaires (88\%) were returned. However, only 120 sets of questionnaires were used in this study due to the lack of information in some questionnaires. In this study, there were 18 males and 102 females. The age categories of this study were 22 years, followed by 20 years and 21 years. In addition, most of the respondents were Malay (77 people), followed by Chinese (32 people) and Indian ( 5 people). In addition, third year students were the most respondents which consisted of 34 people, followed by second year and fourth year student.

\subsection{Instrument}

The research consists of three parts. The first part consists of seven questions that measure the characteristics and background of the students. All questions were related to the background of the respondents, information such as year of course, gender, age, ethnicity, parents' academic level, household income, and closest people. The second part measured on perception of parenting style used by students' parents. Parental Authority Questionnaire (PAQ) was used in this study. This questionnaire consisted of 30 questions and was measuring three types of parenting styles. The breakdown of these items were authoritarian (10 questions), authoritative (10 questions) and permissive (10 questions). This questionnaire had been translated into Malay language by Kwan (2004) because the Malay language is the national language of Malaysia and respondents could answer more accurately with this language. The last part of the questionnaire measured the level of students' self-esteem. Questionnaire of Rosenberg Self-Esteem Scale (RSES) was used in this study. This questionnaire consisted of 10 questions to assess the level of students' self-esteem. This questionnaire had been translated into Bahasa Melayu by Azrul Masiron (2009).

\section{Results}

Table 1 shows the mean scores of students' self- esteem in a faculty at ABC. The mean scores for university students' self- esteem is 3.89. This value indicates that the level of ABC students' self- esteem is high.

Table 1: Self- esteem levels among university students

\begin{tabular}{llll}
\hline & Variable & Min & SD \\
\hline & Self-esteem & 3.89 & 0.537 \\
\hline $\mathrm{N}=120$ & & &
\end{tabular}

Table 2 above shows the mean scores for the dominant parenting style used among the parents of $A B C$ students. The highest mean value is dominant parenting style used by the parents of $A B C$ students. The mean score for permissive parenting styles has the highest score which is 3.925 . This value indicates permissive parenting style is the most dominant style used by parents. Authoritative parenting style has a mean value of 3.916. However, authoritarian parenting style has the lowest mean value of 2.294. 
Table 2: Parenting styles among university students

\begin{tabular}{ccc}
\hline Parenting styles & Min & SD \\
\hline Authoritarian & 2.294 & 0.783 \\
Authoritative & 3.916 & 0.589 \\
Permissive & 3.925 & 0.715 \\
\hline
\end{tabular}

Based on table 3 , we have found that the value is $0.570 *$ and $p$ value $<0.05$ at 0.05 . This clearly shows that there is a positive significant relationship between parenting style and self-esteem. Therefore, the hypothesis which states that there is no significant relationship between parenting style and students' self- esteem is not acceptable.

Table 3: Pearson coefficients between parenting style and self esteem

\begin{tabular}{ccc}
\cline { 2 - 3 } & Variable & Self-esteem \\
\cline { 2 - 3 } & Parenting styles & $0.570^{\star \star}$ \\
\hline
\end{tabular}

Table 4 shows the relationship between parenting style and self- esteem among students in a faculty at $A B C$. By using Pearson correlation analysis, authoritarian parenting style has negative correlation with self- esteem $(r=-0611, p<0.01)$. In addition, the permissive parenting style has positive correlation with self-esteem $(r=0.420, p<0.01)$ and an authoritative parenting style has positive correlation with self- esteem $(r=0.471, p<0.01)$. All types of parenting styles have a significant relationship with self- esteem. Therefore, the hypothesis states that there is no significant relationship between parenting style and students' self- esteem is not acceptable.

Table 4: Pearson coefficients between parenting style and self esteem

\begin{tabular}{cc}
\cline { 2 - 3 } Independent variables & Self-esteem \\
\cline { 2 - 3 } & $-0.611^{* *}$ \\
Authoritarian parenting style & $0.420^{\star *}$ \\
Authoritative parenting style & $0.471^{\star *}$ \\
\cline { 2 - 2 } Permissive parenting style &
\end{tabular}

\section{Discussion and Conclusion}

The results of this study have shown that the level of self-esteem among ABC students is high. According to Lee (2011), parents who adopt a suitable parenting style allow the children to develop a high level of self-esteem. The results of this study show that the most dominant parenting style practiced by the parents of university students is permissive parenting style and this trend is positively associated with students' self-esteem. Permissive parenting style that is high on dimensions of responsiveness and responsiveness are associated with high level of self-esteem (Sigelman \& Rider, 2008). This is because the parents who are high in the dimension of responsive are always giving love and support to their children's decision. This situation allows the children to be more confident in making decisions and indirectly develop a high levels of self-esteem.

According to Parker and Benson (2004), an individual who has high level of self-esteem has characteristics such as confidence, emotional stability, social competence, and good cognitive development. According Philipchalk (1995) individuals are more likely to solve their problems when they have high level of self-esteem.

\subsection{Permissive parenting style is the most dominant parenting style used by parents}

The result is similar to the findings of Gracia \& Gracia (2009) that permissive parenting style is the most dominant parenting style practiced in Spain. According to Driscoll, Russell \& Crocket (2008), permissive parenting style has spread from generation to generation. In fact, the results of this study are not consistent with previous studies, such as most of the Asians practice authoritarian parenting style (Alsheikh \& Parameswaran, 2010). In addition, the findings of Salasiah (2011) showed that the authoritarian parenting style is the most dominant parenting styles practiced by parents of secondary school students in the district of Batu Pahat. The difference in the results of this study is due to majority of respondents in this study were Malays. 
Findings of Zainal, Li, \& Arfah (2003) found that Malays and Chinese parents in Malaysia do not practice authoritarian parenting style. The findings of Zervides \& Knowles (2007) stated that the trend of parenting style among Asians has changed. This is because the results of the study Shwalb, Nakazawa, Yamamoto \& Hyun (2004) showed that the parenting style practiced by the Japanese parents are permissive parenting style but not authoritarian parenting styles. Therefore, we understand that not all Asians adopt an authoritarian parenting style.

This phenomenon may be due to the change in generation and ways of life. Zervides \& Knowles (2007) states that there is a change in parenting style practices of parent in two generations, namely Greece - Australia. Parenting style of Greece - Australia has changed from authoritarian parenting style to a permissive parenting style. This is caused by change in human life such as busy, increasingly competitive, and parents spending less time to communicate with their children (Zervides \& Knowles, 2007). Busy parents do not have time to make a request to their children, so they can only fulfil the requirement of their children as much as possible so that children feel themselves loved by their parents. Therefore, life style affects the dominant parenting style practiced by parents.

Adolescents' perception toward parenting styles practice by their parent is important in shaping their own self esteem. Smith (2007) argues that if adolescents interpret the lack of parental control as disinterest or disapproval, then teens will blame parents for not guiding them and so on. However, if adolescents interpret the permissive parenting style of their parents as placing more trust and confidence in their abilities or their capabilities and to train them to become more independent and dedicated, teenagers will behave and think positively towards their parents. If students have positive self-esteem level then they are likely to interpret the behavior of their parents in a positive way.

\subsection{The parenting style has a significant positive relationship with the students' self-esteem}

This is meant that the adolescents' level of self-esteem is influenced by parenting style. According to Bulanda \& Majumdar (2008), the formation of positive self-esteem depends on a positive response from the people around, especially parents. The attitude of parents who concern on children succeed make children feel desired, allow children to explore competitive and develop their own social world. In fact, the attitude of parents who refuse and control children are most likely to contribute decisively low self-esteem in children.

The results of this study also found that the parents are an important component in the family system and also as an individual who is responsible for the formation of self-esteem for children. Research of Rosmaliza (2005) showed that no significant differences in parenting styles and students' self-esteem among working mothers and non-working mother. This is because a mother's love is an essential element for the formation of self-esteem of children (Rosmaliza, 2005). Working mothers can also give affection to their children.

The results of this study are equivalent to previous studies (Kwan, 2004; Kamilah Noordin, 2006; Lee, 2011; Parker \& Benson, 2004; Rosmaliza Mohammad, 2005; Md. Zahir, 2009) in which the study showed that there is a positive relationship between parenting style and adolescent self-esteem. Teens who are grown up in a family that has positive qualities such as love each other, work together and concerned toward each others can develop high levels of selfesteem (Kwan, 2004). While teenagers who are grown up in the broken family, selfish and ignore each other tend to develop low levels of self-esteem (Kwan, 2004). This evident proves that family is influencing the formation of good behavior and high level of self-esteem in adolescents.

Moreover, Beckett (2002) showed that self-esteem is formed since childhood and constantly changing based on past experiences with parents. This fact shows the importance of parenting style on students' self-esteem. In addition, the study carried out by Steinberg (2001) in the United States found that teens who have firm and friendly parenting style can adapt better than those who have a different parenting style. Teens who have a firm and friendly parenting style is less depression, anxiety, antisocial behavior, self-discipline and high self-esteem.

\subsection{Negative correlation between authoritarian parenting style and adolescent self-esteem}

This shows that the negative interaction of parents can cause teens to feel incapable and useless. The results of this study are similar with the findings of Kwan (2004) and Wan Mohd Agil (2009) in which an authoritarian parenting style is negatively related to student self-esteem.

According to Baumrind (1996), parents who practice authoritarian parenting style tend to control and evaluate the behavior and attitudes of their children and demand a set of behavioral standards. This parenting style also assesses compliance and penalties as a good thing and strictly control the children's behavior. The children are not allowed to deny the future directions given and have to comply with the rules set by their parents. Too much control over the children can cause low self-esteem levels in them (Smith, 2007). 
Authoritarian parenting style can cause unhealthy youth development. Hoongeboom, Stams, Hermanns \& Peetsma (2008) had demonstrated an association between negative emotional and behavioral problems of the children with authoritarian parenting style practiced by their mother. In addition, Joussement, Vitaro, Edward, Sylvia Cole, Daniel, Mark and Richard (2008) found that parents' early education and divorce are associated with children violent behavior. In addition, this study also found that the mothers who are practicing an authoritarian parenting style is an important factor in causing children to behaving violently.

The findings of Repettiet, Taylor \& Seeman (2002) stated that strict control of parents in educating their children should be done in more careful ways. This is because strict control is positively related to children's weak mental health. The findings of Caron, Weiss, Harris, \& Catron (2006) also found that the teens who are receiving an authoritarian parenting style may result in the low level of self-esteem and self-efficiency. Even the finding of Bee \& Boy (2002) had also found that the rejection of parenting style from the parents can cause the teen to involve in deviant behavior and delinquent due to less attention and support from their parents. In addition, authoritarian parenting style can cause the children to have poor social skills, behave aggressively or too passive, and have mood swings (Bee \& Boy, 2002).

The authoritarian parenting style can cause children to develop negative traits. A study conducted by Zhou, Eisenberg, Wang \& Reiser (2004) on the children who go to Chinese school and are treated in authoritarian parenting style had found a positive association with low social skills, follow the rules, irritability, and poor self-control. These features can cause the children to feel angry at a small problem. In addition, Steinberg, Blatt \& Cauffman (2006) showed that the children treated in authoritarian parenting style have high rate in juvenile. In addition, the findings of Smith (2007) had shown that the authoritarian parenting style causes low self-esteem and self-efficiency.

The results of this study and previous studies have found that the parents who adopt an authoritarian parenting style are more likely to have a negative impact of the psychosocial development to the children and affect the adjustment and formation of self during the adolescent stage of development.

\subsection{Significant correlation between permissive parenting style and adolescent self-esteem}

The positive correlation between permissive parenting style and adolescent self-esteem shows that the higher the responsiveness of parents on teens, the higher the level of self-esteem of adolescents. According to Baumrind (1996) parents who adopt a permissive parenting style is the parents who do not impose punishment, accept and fulfil all of the children desire. This kind of parents discuss to their children about the results of the policy, explain family rules and make request to children that may be applicable to their responsibilities and rules of conduct. Permissive parenting style also act as a resource to the children when needed, allow children to plan each activity that they are interested, avoid implementation of control and do not encourage children to comply with a standard that is defined externally (Baumrind, 1991).

Positive relationship between permissive parenting style and self-esteem can be explained by the model of Maccoby and Martin. Maccoby \& Murray (1983) stated that authoritative and permissive parenting style is high on the dimension of responsiveness. According to Dwairy \& Menshar (2005), parents who are high on the dimension of responsiveness always give love and support to the children's decision. This situation allows the children to develop confidence of making decisions and indirectly developing high levels of self-esteem. Therefore, high responsiveness is associated with high level of self-esteem (Sigelman \& Rider, 2010). This can explain why university students who grew up with authoritative and permissive parenting style have a high level of self-esteem.

A study conducted by Gracia \& Gracia (2004) found that there are certain culture practices of permissive parenting styles have the same relationship but better results than authoritative parenting style. For example, Kim \& Rhoner (2002) found that the parents who adopt an authoritative parenting style show poorer academic achievement of adolescents when comparing to the parents who adopt a permissive parenting style. The results of this study and the previous study have shown that the parents who adopt a permissive parenting style are more likely to have a positive impact on the psychosocial development of children and sometimes the effect is better than authoritative parenting style.

\subsection{Positive relationship between authoritative parenting style and adolescent self-esteem}

This means that the authoritative style used by the parents has a positive effect on the development of adolescents' selfesteem. The study was supported by research conducted by Weiten, Lloyd, Dunn \& Hammer (2008); Rathus (2007) which said there is a strong positive relationship between authoritative parenting style and students' self-esteem. Authoritative parenting style can produce healthy child development environment (Jas Laille Suzana, 2000). This is because authoritative parents offers a balance between the freedom and autonomy. This makes the children develop and 
believe about their own ability and know about the limitations of the code of conduct. In addition, parents are willing to give evidence and listen to their children but at the same time they are strict so their children to have the ego strength and self-discipline.

Children who receive authoritative parenting style are associated with positive behaviors and have good social skills (Dwairy\& Achoui, 2006). The findings of Furnhman \& Cheng (2000) found that self-esteem is not only associated with joy but also as an intermediate variable between parenting style, especially with authoritative parenting style and joy. In addition, the findings of Kim and Chung (2003) at Korean American students found that the students who are developed with authoritative parenting style have satisfactory academic achievement. This is because support and love from authoritative parenting style allows the children to develop the intrinsic motivation in their academic activities.

Adolescent who are treated in authoritative parenting style are seen to have many positive attributes. Children grown under the authoritative parenting style have a cheerful nature, empathy and high social competence, independent and responsible (Kamilah Noordin, 2005). They are also love to explore new things around them. The exploration of the environment is very important for children as they can gain experience and knowledge and then generate their minds. The nature of exploring new things is actually provide great advantages to young people in their process to socialize with people and the environment (Kamilah Noordin, 2005). According to Smith (2007), children who are developed from authoritative parenting style have high self-esteem and self-efficiency. Both of these properties allow the student to encounter lesser experienced of homesick and show more stable emotions and behaviors during adjustment to college life (Smith, 2007).

\section{Limitations of the Study}

This study could not involve many respondents due to the lack of time. Besides this, only students in a faculty at ABC involved in this study. Therefore, the results of this study cannot generally apply over other universities. There is an imbalance in the ratio of male and female students in this study. This is because most of the courses in the faculty of management have higher female students comparing to male students. For example, the second year psychology student are only 8 males but 30 females. In addition, the data of student self-report may be affected due to their social desirability (the desire to look good by others) that may affect the validity of this study. Furthermore, the complex nature of parenting and parenting style may not be the only factor that determines the students' self-esteem. For example, achievement motivation, teachers and peers are also contributing to the students' self-esteem. Therefore, further work is needed on the limitations of this study in the future in order to fill the gaps in research on this topic.

\section{Recommendations for Future Studies}

This study examines three types of parenting styles. However, future studies are encouraged to use more than three type of parenting style. This is because the relationship between the parenting style and students' self-esteem can be extended. In addition, it is important to study more types of parenting styles in shaping students who have a high level of self-esteem, confidence and skill. This study conducted only in one faculty, it does not represent parenting styles and self-esteem throughout Malaysia. In further studies, the samples size can be increased and a comparative study can be made between public and private universities in Malaysia.

\section{Acknowledgement}

Authors wish to acknowledge the Malaysian Ministry of Higher Education and Universiti Teknologi Malaysia under the Research Grant (Vot. 4F349) for supporting and sponsoring this publication.

\section{References}

Gota, A. A. (2012). Effects of parenting styles, academic self-efficacy, and achievement motivation on the academic achievement of university students in Ethiopia. Edith Cowan University Unpublished PhD Theses.

Alsheikh, N. O., \& Parameswaran, G. (2010). Parenting Style, self-esteem and student performance on the United Arab Emirates. Journal Children and Family Studies, 13(1), 1-21.

Avidan, M., Melissa, S., Sarah. N, \& Danielle. K (2007). Maternal and parental styles in adolescents associations with self-esteem, depression and life satisfaction. Journal Children and Family Studies, 16, 39-47.

Azizi Yahaya \& Jaafar Sidek (2006). Counseling Series: Establish the identity of the adolescents (2nd edition). Bentong: PTS Professional Publishing Sdn. Bhd. 
Baumrind, D. (1991). The influence of parenting style of adolescent competence and substance use. Journal of Early Adolescence, 11, 56-95.

Baumrind, D. (1996). The discipline controversy revisited. Journal of Family Relations, 45, 405-414.

Beckett, C. (2002). Human growth and development. London: SAGE Publications Ltd.

Bee, H. \& Boy, D. (2000). Life span development. Boston: Allyn and Bacon.

Brown, J. D., \& Dutton, K. A. (1995). The thrill of victory, the complexity of defeat: self-esteem and people's emotional reactions to success and failure. Journal of personality and social psychology, 68(4), 712.

Bulanda, R. E., \& Majumdar, D. (2008). Perceived parent-child relations and adolescent self-esteem. Journal of Child and Family Studies, 18, 203-212.

Caron, A., Weiss, B., Harris, V., \& Catron, T. (2006). Parenting behavior dimensions and child psychopathology: Specificity, task dependency, and interactive relations. Journal of Clinical Child and Adolescent Psychology, 35(1), 34-45.

Caporella, D. (2007). What lies beneath: Parenting style and implicit self-esteem. Retrieved from http://ezinearticles.com/?Has-TodaysModern-LifestyleInfluenced-Parenting-Style\&id=503650

Chao, R. K. (1994). Beyond parental control and authoritarian parental style: understanding Chinese parenting through the cultural notion of training. Journal of Child Development, 65 (4), 1111-1119.

Cheung, C. S., \& McBride-Chang, C. (2008). Relations of perceived maternal parenting style, practices, and learning motivation to academic competence in Chinese children. Merrill-Palmer Quarterly (1982), 1-22.

Cohen, D. A., \& Rice, J. (1997). Parenting styles, adolescent substance use, and academic achievement. Journal of Drug Education, 27(2), 199-211.

Coopersmith, S. (1967). The antecedents of self-esteem. Consulting Psychologists Pr.

Driscoll, A.K., Russel. S.T., \& Crocket, L. J. (2008). Parenting styles and youth well-being across imigrant generations. Journal of Family Issues, 29(2), 182-194.

Dwairy, M., \& Achoui,M. (2006). Parenting Styles in Arab Societies: A First Cross-Regional Research Study. Journal of Cross-Cultural Psychology, 37(3), 1-18.

Dwairy, M., \& Menshar, K. E. (2005). Parenting style, individuation, and mental health of Egyptian adolescents. Journal of Adolescence, 29, 103-117.

Elham Dehyadegary, Siti Nor Yaacob, Rumaya Juhari \& Mansor Abu Talib (2012). Relationship between parenting style and academic achievement among Iranian adolescents. Asian Social Science, 8(1), 156-160.

Furnhman, A., \& Cheng, H. (2000). Perceive parental behavior, self-esteem and happiness. social psychiatry and psychiatry epidemiology. London: SAGE Publications Ltd.

Garcia, F., \& Gracia, E. (2009). Is always authoritative the optimum parenting style? Evidence from Spanish families. Journal of Adolescence, 44 (173), 101-131.

Hoogeboom, M., Greeth, J. J.M. S., Hermanns, M.A \& Thea T.D Peetsma (2008) Parenting style as a mediator between children's negative emotionality and problematic behavior in early childhood. Journal of Genetic Psychology, 169 (3), 209-226.

Hsieh, C. L. (1998). Relating parenting styles and children's temperament to behavioral adjustment and academic achievement of Taiwanese children (Unpublished Doctoral dissertation, Texas Tech University).

Huver, R. M., Otten, R., de Vries, H., \& Engels, R. C. (2010). Personality and parenting style in parents of adolescents. Journal of Adolescence, 33(3), 395-402.

Jas L., S. (2000). Psychology of Children and Youth. Kuala Lumpur: Dewan Bahasa and Kuala Lumpur Inheritance.

Joussement, M. , Frank. V., Edward, D. B, Sylvia, C., Daniel, S. N., Mark. Z., \& Richard E. T. (2008). Controlling parenting and physical aggression during elementary school. Journal of Child Development. 79(2), 411-425.

Kamilah bt Noordin. (2005). The relationship between self-concept, motivation and parenting style and achievement. Unpublished Bachelor's thesis, Universiti Teknologi Malaysia, Skudai.

Kim, H., \& Chung, R.G. (2003). Relationship of recalled parenting style to self-perception in Korea American college students. Journal of Genetics Psychology, 164(4), 481-492.

Kim, K \&. Rhoner, P.R. (2002). Parental warmth, control and involvement in schooling: Predicting academic achievement among Korean American adolescence. Journal of Cross-Cultural Psychology, 33(2), 127-140.

Kwan, S. L. (2004)The relationship between parenting style and adolescent self- esteem , Unpublished undergraduate thesis, Universiti Kebangsaan Malaysia, Kuala Lumpur.

Leary, M. R., \& MacDonald, G. (2003). Individual differences in self-esteem: A review and theoretical integration. Handbook of self and identity, 401.

Lee, Y. C. (2011). A study of relationship between parenting styles and self-esteem: self-esteem's indicator-parenting styles (Doctoral dissertation, UTAR).

Li, Y., Costanzo, P. R., \& Putallaz, M. (2010). Maternal socialization goals, parenting styles, and social-emotional adjustment among Chinese and European American young adults: Testing a mediation model. The Journal of Genetic Psychology, 171(4), 330-362.

Maccoby, E. E. \& Murray, J. A. (1983). Socialization in the context of the family: Parent-child interaction. Handbook of child psychology, 4, 1-101.

Martinez, I., \& García, J. (2007). Impact of parenting styles on adolescents' self-esteem and internalization of values in Spain. The Spanish Journal of Psychology, 10(2), 338- 348.

Md Zahir Abdul Hamid (2009). The relationship between parent and child relationship with students' self- esteem in one secondary 
school in Taiping. Unpublished Bachelor thesis, Universiti Pendidikan Sultan Idris

Mruk, C. J. (2006). Self-esteem research, theory, and practice: toward a positive psychology of self-esteem. New York: Springer Publishing Company.

Nancy, D. (2011). Parenting Style and Its Correlates. ERIC Digest. Clearinghouse on Elementary and Early Childhood Education.

New, R. S., \& Cochran, M. (Eds.). (2007). Early Childhood Education: The countries (Vol. 4). Greenwood Publishing Group.

Norhusna Abu Bakar (2009). Parental nurturing styles and levels of depression among students at risk of living in the district. Unpublished Bachelor Thesis. Tanjung Malim: Universiti Pendidikan Sultan Idris.

Norhayati Alias (2009). The relationship between parents' nurturing style with adolescent self-concept (FELDA). Unpublished Bachelor thesis, Universiti Pendidikan Sultan Idris.

Nuraini Nawwar (2009). The relationship between parenting style and students' self- disclosure in a secondary school in Kuala Kangsar. Unpublished thesis. Tanjung Malim: Universiti Pendidikan Sultan Idris.

Parker, J. S. \& M. J. Benson (2004). Parent-adolescent relations and adolescent functioning: self-esteem, substance abuse, and delinquency. Journal of Adolescence, 39(155), 519-530.

Philipchalk ,R. P.(1995) Invitation to social psychology. Canada: Harcourt Brace College Publishers

Repettiet, R.L., Taylor, S.E., \& Seeman, T.E. (2002). Risky families: Family social environments and the mental and physical health of offspring. Psychological Bulletin, 128, 330-366.

Robiatun Nur binti Zabidi (2002). Parenting styles and relationships with parents of delinquent's self-concept deviant behavior. A case study around Tunas Bakti Taiping. Unpublished Bachelor thesis. University of Malaysia, Kuala Lumpur.

Rosmaliza Bt Mohammad (2005). Parenting styles of mothers and their relationship with self- esteem of children. Unpublished Bachelor thesis. University of Malaysia, Kuala Lumpur.

Ross, R., Zeller, R., Srisaeng, P., Yimmee, S., Sawatphanit, W., \& Somchid, S. (2006). Self-esteem, parent-child interaction, emotional support, and self-perception among Thai undergraduate nursing students. International journal of nursing education scholarship, 3(1), 189-198.

Salasiah Binti Khairollah (2011). Parenting style that influenced the formation of the student Islamic personality. Unpublished Bachelor thesis. Universiti Teknologi Malaysia, Skudai.

Shwalb, D. W., Nakazawa, J., Yamamoto, T. O. S. H. I. Y. A., \& Hyun, J. (2004). Fathering in Japanese, Chinese, and Korean cultures. The role of the father in child development, 146-181.

Sigelman, C. K., \& Rider, E. A. (2010). Life span human development. Cengage Brain.

Smith, G. J. (2007). Parenting Effects on Self-Efficacy and Self-Esteem in Late Adolescence and How Those Factors Impact Adjustment to College. Online Submission.

Steinberg, L., Blatt-Eisengart, I., \& Cauffman, E. (2006). Patterns of competence and adjustment among adolescents from authoritative, authoritarian, indulgent, and neglectful homes: A replication in a sample of serious juvenile offenders. Journal of Research on Adolescence, 16(1), 47-58.

Steinberg, S. (2001). The ethnic myth: Race, ethnicity, and class in America. Beacon Press.

Wan Mohd Agil Mat Yamin (2009). The relationship between parenting styles and self- esteem among students at one school in the district. Unpublished Bachelor thesis. Universiti Pendidikan Sultan Idris.

Wei, M. L. (2008). The relationship between parental behavior and self- esteem among adolescents. Unpublished Bachelor thesis. Universiti Teknologi Malaysia, Skudai.

Weiten, W., Lloyd, M. A., Dunn, D. S., \& Hammer, E. Y. (2008). Psychology applied to modern life: Adjustment in the 21st century (9th ed.). Florence: Cengage Learning.

Zainal Ahmad Zaimani, Li Yee Wah \& Arfah Sulaiman (2003). Parenting styles and Malay Chinese family child: A comparison of the National Family seminar proceedings, Unpublished Bachelor thesis. Universiti Kebangsaan Malaysia, Kuala Lumpur.

Zervides, S., \& Knowles, A. (2007). Generational changes in parenting styles and the effect of culture. E-Journal of Applied Psychology, 3(1), 65-75.

Zhou, Q., Eisenberg, N, Wang, Y, \& Raiser, M. (2004). Chinese children effortful control and dispositional anger/ frustration: Relations to parenting styles and children functioning. Journal of Development Psychology. 40, 352-366. 